\title{
TRADISI MINTA HUJAN ARMAROHIMIN
}

\section{Ilham Halid}

\section{Abstract}

Armarohimin is one of Nagari Taram tradition which ask rain to God. This paper describes Armarohimin ceremony, explain the religion (Islam) aspect in this ceremony context, and the ceremony function in the society itself. Nowadays, there are two gaps which accept and reject with this tradition. Indeed, this tradition reflect the society lives which is can't be seperated from Islam development in Sumatera.

Key word: Armarohimin, Minangkabau, minta hujan, tradisi

\section{Pengantar}

Jenis-jenis tradisi lisan di Minangkabau sangat banyak, di antaranya Tradisi Pasambahan, Tradisi Bailau, Tradisi Mangaji Rukun, Tradisi Ulu Ambek. Selain nama-nama tradisi yang tercantum di atas masih ada tradisi yang belum dikenal oleh masyarakat Minangkabau secara umum, yakni tradisi minta hujan. tradisi minta hujan tidak terdapat di semua daerah di Minangkabau. Tradisi ini hanya terdapat di daerah-daerah yang memiliki curah hujan yang relatif rendah. Salah satu daerah yang memiliki curah hujan rendah yaitu Nagari Taram Kecamatan Harau Kabupaten Limapuluh Kota. Tradisi minta hujan di Nagari Taram ini dikenal dengan nama Armarohimin.

Tradisi Armarohimin dilaksanakan oleh masyarakat Nagari Taram pada saat musim kemarau. Masyarakat Taram tidak melaksanakan Shalat Istisqa', tetapi melakukan tradisi Armarohimin ini. Biasanya tradisi Armarohimin dilaksanakan apabila hujan tidak turun hujan selama dua sampai tiga bulan. Sebelum tradisi ini dilaksanakan, terlebih dahulu masyarakat melaksanakan tradisi Tulak Bala dan doa Qunut. Doa Qunut dilaksanakan setelah Shalat Jumat selama dua sampai tiga kali pelaksanaan

WACANA ETNIK, Jurnal IImu Sasial dan Humaniara. ISSN 2098-8746. Volume 2, Nomor 1, April 2011. Halaman 11 - 24 Padang: Pusat Studi Informasi dan Kebudayaan Minangkabau (PSIKM) dan Sastra Daerah FIB Universitas Andalas 
shalat Jumat. Apabila hujan tidak juga turun barulah mereka melaksanakan Armarohimin.

Armarohimin dilaksanakan setelah Shalat Isya, dengan cara mengelilingi kampung menuju makam para ulama yang dianggap memiliki tingkat keimanan yang tinggi. Masyarakat Taram beranggapan bahwa dengan dengan mengucapkan doa di makam para ulama tersebut, doa mereka untuk meminta hujan akan cepat terkabul, karena dibantu oleh para pendahulu mereka. Akan tetapi, bagi masyarakat Taram yang memiliki pemahaman yang berbeda tentang Armarohimin, menganggap kegiatan ini sebagai kegiatan mengunjungi tempat-tempat yang dianggap keramat. Anggapan ini berkembang pada masyarakat Taram karena mereka menganggap hujan ditahan oleh jin-jin penunggu tempat-tempat keramat tersebut.

Pelaksanaan Armarohimin dilakukan selama tiga malam berturutturut menuju tempat-tempat yang berbeda. Kegiatan ini dipimpin oleh seorang yang dituakan dalam Surau Tuo Taram, dan anggotanya terdiri dari garin-garin mushalla, guru-guru mengaji, para jemaah, dan pemuda. Biasanya, semakin banyak orang yang ikut dalam ritual Armarohimin, maka dipercaya akan mempercepat terkabulnya permohonan.

Pada saat sekarang ini, tradisi Armarohimin yang ada di Nagari Taram hampir tidak pernah dilakukan lagi. Hal ini disebabkan oleh beberapa faktor, antara lain Nagari Taram tidak mengalami kemarau yang terlalu panjang. Faktor lainnya, disebabkan oleh semakin baiknya sistem irigasi di daerah tersebut. Walaupun Taram mengalami kemarau, namun air tetap tersedia untuk kebutuhan hidup sehari-hari dan pengairan pertanian. Melihat keadaan yang demikian, diperkirakan tradisi yang sudah diwarisi secara turun-temurun ini akan hilang karena kebutuhan masyarakat terhadap tradisi mulai berkurang. Oleh karena itu, penulis menjadikan tradisi Armarohimin ini layak dijadikan sebagai objek penelitian untuk mendokumentasikan tradisi tersebut.

Penelitian ini berupa pendeskripsian objek sebagai usaha pendokumentasian tradisi tersebut, sehingga tidak mengalami kepunahan. Lebih lanjut, tradisi dianalis menggunakan teori yang dikemukan oleh Danandjaja, bahwa folklor mempunyai beberapa ciri yang membedakannya dengan kebudayaan lain. Salah satu ciri tersebut menyebutkan bahwa folklor mempunyai fungsi dalam kehidupan kolektifnya (1986: 3-4). 


\section{Landasan Teori}

Bentuk-bentuk folklor dapat dikelompokkan dalam tiga golongan, yaitu folklor lisan, folklor setengah lisan, dan folklor bukan lisan. Folklore lisan meliputi: (a) bahasa rakyat seperti julukan tradisional; (b) ungkapan tradisional seperti pribahasa; (c) pertanyaan tradisional, seperti teka-teki; (d) puisi rakyat, seperti gurindam dan pantun; (e) cerita rakyat, seperti mite, legenda dan dongeng; (f) nyanyian rakyat. Folklor setengah lisan berupa kepercayaan rakyat, teater rakyat, dan tarian rakyat. Folklor bukan lisan, seperti arsitektur dan obat-obatan rakyat (Danandjaja, 1984: 20).

Menurut Bascom, dalam kajian ilmui-lmu sosial folklor berfungsi sebagai; (a) sistem proyeksi, yakni sebagai alat pencerminan angan-angan suatu kolektif; (b) alat pengesahan pranata-pranata dan lembaga-lembaga kebudayaan; (c) alat pendidikan anak; (d) alat pemeriksa dan pengawas agar norma-norma masyarakat selalu dipatuhi oleh anggota kolektifnya (sebagai alat control sosial) (dalam Danandjaja. 1982: 19).

Dengan berpedoman pada keempat fungsi yang telah dikemukan oleh Bascom di atas, maka penelitian terhadap tradisi minta hujan armarohimin di Nagari Taram ini akan dilakukan. Dengan anggapan bahwa tradisi tersbut merupakan proyeksi keinginan dan harapan masyarakat Nagari Taram. Di samping itu, tradisi ini juga merupakan satu alat yang digunakan sebagai upaya mengesahkan suatu system tingkah laku dalam kehidupan sosial mereka, termsuk kehidupan beradat. Bahkan dahulu tradisi ini merupakan sebagai alat pembelajaran dan pendidikan kepada anak-anak mereka terkait budi pekerti dan kecintaan terhadap kebudayaan masyarakat Taram.

\section{Metodologi}

Metode yang digunakan dalam penelitian ini adalah metode penelitian kualitatif. Metode kualitatif adalah prosedur yang menghasilkan data deskriptif berupa ucapan, catatan tertulis ataupun lisan serta perilaku yang dapat diamati dari subyek tersebut, dan langsung menunjukkan perilaku individu-individu yang terlibat di dalamnya secara menyeluruh. Metode ini terutama memusatkan perhatian pada usaha mendeskripsikan, menginventarisasikan dan mengklasifikasikan objek penelitian (Vredenbregt, 1980:4). Namun demikian, penelitian ini difokuskan pada upaya mendeskripsikan keberadaan Tradisi Armarohimin sebagai bagian dari sistem kepercayaan masyarakat Nagari Taram.

keseluruhan data dan informasi terkait dengan keberadaan Tradisi 
Armarohimin dikumpulkan dengan melaksanakan beberapa langkah berikut.

Observasi merupakan cara yang disengaja untuk mengamati perilaku dan perubahan sosial yang tumbuh dan berkembang. Tujuan dari observasi adalah untuk menjadikan gambaran-gambaran kehidupan masyarakat Taram yang berkaitan erat dengan ritual tersebut. Untuk mendapatkan data optimal diperlukan pencatatan, akan tetapi ada hal-hal yang tidak dapat dicatat dalam objek penelitian. Oleh sebab itu, maka diperlukan pemotretan dan perekaman dengan menggunakan alat perekam sebagai alat bantu pengamatan. Dalam penelitian ini, teknik observasi dilakukan untuk mendapatkan data berupa gambar, monografi lokasi penelitian Tradisi Armarohmin di Nagari Taram.

Wawancara dapat dijadikan sebagai suatu proses interaksi dan komunikasi dalam sejumlah variabel (pewawancara, respondens, dan daftar tanyaan) yang memainkan peranan penting (Vredenbergt, 1980:89).

Wawancara dalam suatu penelitian bertujuan untuk menggali pemikiran kontruktif seorang informan menyangkut peristiwa-peristiwa dialaminya yang berhubungan dengan tema penelitian. Informan yang digunakan dalam penelitian ini adalah orang yang mempunyai pengetahuan luas mengenai masalah yang ada dalam penelitian ini.

Di dalam penelitian ini, wawancara dilakukan dengan metode wawancara tidak berencana, oleh karena dalam melakukan wawancara tidak menyusun daftar pertanyaan sebagai pedoman dalam melakukan wawancara. Selain itu bentuk pertanyaan dalam wawancara adalah wawancara tertutup, oleh karena jawaban yang dikehendaki terbatas (Koentjaraningrat dalam Bungin, 2004: 62).

Studi pustaka adalah bagian dari sebuah proposal yang berisikan informasi-informasi yang diperoleh dari jurnal, kertas kerja dan buku. Selain itu studi pustaka juga dapat bermanfaat untuk melakukan penyelusuran referensi dan penelaah referensi. Dalam studi pustaka, penulis mencari berbagai bahan tertulis yang berkaitan dengan objek kajian berupa bukubuku dan dokumen-dokumen lainnya.

Setelah data selesai dikumpulkan dengan lengkap di lapangan, maka tahap berikut yang harus dilakukan adalah analisis data. Tahap ini mengerjakan data untuk mencari kebenaran yang dapat menjawab permasalahan yang diajukan dalam penelitian.

Semua informasi yang diberikan oleh informan dikumpulkan dan 
dipelajari sebagai suatu kumpulan informasi yang utuh dan selanjutnya dianalisis sesuai dengan interpretasi penulis. Untuk menjaga keabsahan data, selama dan sesudah penelitian dilakukan pengecekan pada setiap jawaban yang telah diberikan oleh informan.

\section{Pelaksanaan Armarohimin}

Dilihat dari namanya, asal-usul nama Nagari Taram dapat dibagi atas tiga istilah. Pertama, kata Taram berasal dari kata Taham atau ta oham, yang berarti rendah atau terendam. Hal ini dikarenakan daerah Kapalo Koto nagari berada di tepi Sungai Sinamar yang letaknya agak rendah, sehingga pada waktu musim hujan sering mengalami kebanjiran. Kedua, kata Taram berasal dari kata pohon Toham, merupakan sebuah pohon yang menyerupai damar yang tumbuh di tepi Sungai Sinamar. Nama ini diberi oleh para pedagang yang singgah di nagari ini setelah berlayar menyusuri Sungai Sinamar. Ketiga, kata Taram berasal dari kata Antahan, merupakan istilah yang berkembang pada masa ajaran agama Hindu. Agama Hindu mengenal bentuk pemujaan kepada dewa-dewa. Di dalam penyembahannya mereka membutuhkan sebuah media yang menghubungkan mereka dengan para dewa tersebut. Pada masyarakat TaramHindu, sebagai perantara, mereka memahat sebuah bukit yang terkenal dengan nama Bukik Bulek. Bukit tersebut menyerupai manusia sebagai antahan mereka kepada para dewa.

Ketiga asal usul di atas semuanya dipercayai oleh seluruh masyarakat sebagai asal-usul nama Nagari Taram. Mereka bebas mempercayai salah satu asal-usul nama nagari mereka. Akan tetapi mayoritas masyarakat Nagari Taram lebih cenderung untuk memilih pilihan yang pertama.

Sebelum Tradisi Armarohimin dilaksanakan ada dua rangkaian prosesi yang harus dilakukan terlebih dahulu sebagai tahapan awal. Adapun prosesi tersebut dilaksanakan sebagai berikut:

Pada tahap pertama dilakukan ritual Tulak Bala ${ }^{1}$. Tradisi ini merupakan kegiatan pembuka dari beberapa rangkaian tradisi minta hujan yang ada di nagari Taram. Tradisi ini dilaksanakan apabila nagari Taram dilanda kemarau yang cukup panjang atau merebaknya hama penyakit tanaman pertanian dan perkebunan masyarakat. Hal ini merujuk pada kepercayaan masyarakat Taram bahwa datangnya kemarau panjang ditandai dengan mewabahnya hama penyakit tanaman.

Tahap kedua adalah rapat Tuanku 21. Setelah hasil musyawarah

$1 \quad$ Wawancara dengan Bpk Warwan pada tanggal 20 September 2008. 
pengurus Surau Tuo telah menyepakati untuk melakukan tradisi Tulak Bala, maka barulah Tuanku 21 diundang untuk melaksanakan rapat. Agenda rapat berisi tentang pembahasan pengaduan masyarakat yang telah diterima pengurus Surau Tuo. Selanjutnya mengenai waktu pelaksanaan dan rute yang akan dilalui.

Agenda berikutnya membahas tentang kemungkinan kedua. Seandainya tradisi Tulak Bala tidak memberikan hasil yang baik, maka akan dilakukan Doa Qunut sebagai kelanjutan dari tradisi Tulak Bala. Sebagai agenda terakhir, pembahasan tentang kemungkinan pelaksanaan tradisi Armarohimin. Tradisi ini dapat dilakukan apabila cara pertama dan kedua tidak juga bisa mengantisipasi datangnya kemarau.

Tahap ketiga merupakan prosesi Tulak Bala. Pada hari yang telah ditentukan para peserta Tulak Bala berkumpul di Surau Tuo. Disini mereka diberi pengarahan tentang tempat diadakan tradisi ini. Setelah pengarahan selesai, maka semua berjalan menuju tempat diadakannya Tradisi Tulak Bala. Setelah sampai di tempat pelaksanaan, mereka berjalan menyisiri persawahan batas jorong sambil membaca Tahlil dan doa (sama dengan doa Armarohimin).

Pelaksanaan prosesi ini hanya dilakukan satu kali dan dipimpin oleh imam yang juga sama dengan imam pelaksanaan Tradisi Armarohimin. Prosesi ini dilalukan pada siang hari dengan tujuan petani yang sedang berada di sawah dapat ikut serta dalam pelaksaan. Adapun tujuan pelaksanaan tradisi ini untuk memohon dihilangkannya hama penyakit dan diturunkan hujan.

Setelah dilakukan ritual Tulak Bala selanjutnya akan dilakukan Doa Qunut yang merupakan rangkaian tradisi minta hujan. Doa Qunut dilaksanakan apabila prosesi Tulak Bala belum membuahkan hasil. Doa ini dilaksanakan tiga minggu setelah prosesi Tulak Bala, dilaksanakan selama tiga kali pelaksanaan shalat Jumat secara berturut-turut (tiga Minggu). Pada hari pelaksanaanya, sebelum Khatib naik mimbar pengurus mesjid memberitahukan bahwa pada shalat Jumat ini kita akan melaksanakan Doa Qunut. Biasanya khatib yang mengerti, sebelum menutup khotbah keduanya akan membacakan doa minta hujan sebagai penanda pelaksanaan doa Qunut. Pembacaan doa Qunut dilakukan setelah bacaan Iqtidal pada rakaat kedua shalat jumat. Sehabis shalat Jumat dilakukan Tahlil bersama dan pembacaan doa Armarohimin.

Menurut narasumber kata Armarohimin sendiri dalam konteks tradisi 
minta hujan di Nagari Taram tidak memiliki arti khusus. Armarohimin diambil dari bahasa Arab (Al-Quran) yang berarti minta hujan.

Armarohimin dibawa oleh seorang ulama Taram yang bernama Haji Kamin dari Mekkah. Beliau merupakan seorang ulama yang cukup tersohor di zamannya. Sewaktu menunaikan ibadah haji, beliau memperoleh pengetahuan tentang Armarohimin ini dari masyarakat Mekah. Oleh karena ketertarikan beliau terhadap Tradisi Armarohimin ini, beliau mencoba mempraktekkan tradisi ini di kampung halamannya (Taram). Oleh karena watak kepemimpinannya yang disukai oleh warga, maka Tradisi Armarohimin diterima secara terbuka oleh masyarakat Taram untuk menggantikan shalat Istisqa dalam memohon turunnya hujan.

Peserta yang diperbolehkan untuk mengikuti Armarohimin hanya bagi kaum pria. Hal ini disebabkan karena tradisi ini dilakukan pada malam hari.

Adapun waktu pelaksanaan Tradisi Armarohimin dilaksanakan apabila Nagari Taram mengalami musim kemarau selam tiga sampai enam bulan. Biasanya tradisi ini dilaksanakan atas permintaan warga atau petani yang mulai merasakan musim kemarau. Setelah mendapat laporan dari warga, maka mulailah diundang Tuanku 21 untuk membahas masalah ini.

Akan tetapi, setelah mendapat laporan dari warga tidak serta merta Tradisi Armarohimin langsung dilaksanakan. Terlebih dahulu dilaksanakan tradisi Tulak Bala. Tradisi sebagai tradisi pembuka dalam menurunkan hujan. Dilaksanakan pada siang hari. Apabila prosesi ini gagal, maka dilanjutkan dengan Doa Qunut. Doa Qunut dilaksanakan setelah shalat Jumat. Doa ini dilasanakan selama tiga kali pelaksanaan Shalat Jumat secara berturutturut. Apabila hujan tidak juga kunjung turun atau tidak adanya indikasi akan turunnya hujan, maka mulailah pengurus mesjid berserta Tuanku 21 mengadakan pertemuan untuk mengatur jadwal yang tepat untuk melakukan Tradisi Armarohimin. Setelah keputusan musyawarah didapat, maka disebarkanlah hasil ini kepada warga agar dalam prosesinya warga turut andil.

Tempat pelaksanaan tradisi Armarohimin diawali dari Surau Tuo Taram dan dilanjutkan dengan berjalan menuju Ulu Banda yang ada disetiap jorong di Nagari Taram.

Pada waktu dilakukan prosesi ritual Armarohimin dilakukan pembacaan doa yang dipimpin oleh imam yang dituakan dalam ritual ini. Berikut transkripsi beserta terjemahan doa yang dibaca pada waktu 
Ilham Halid

pelaksanaan Tradisi Armarohimin.

\section{دعاء منتاءهجان | مراحمين}

Doa Minta Hujan

اعوذ باله من الثيطان الرجيم* بسم اله الرحمن الرحيم

Audzubillahi minasyaitonirrojim*Bismillahirrohmanirrohim

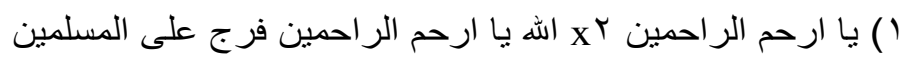

1. Yaa Arhamarrohimin 2x, Allahu ya Arhamarohimin farija alalmuslimin

$$
\text { r }
$$

2. Yaa rabbana yaa karim ya rabbana yaa rahim-Allahu yaa juwada yaa halim wa antal mu'in

$$
\text { r) وليس نرجو سواك فقد رك الله دار - الله قبل الفنا و الخلق يوم الدنيا ودين }
$$

3. Walaisa narojausuka fakodrikallahu daro-Allahukablalfana walkholki yauma adduniawadina

$$
\text { ع ) ومالنا ربنا سو الك يا حسبنااله يا ذا لعلي يامهين يا قوي يامتين }
$$

4. Wamaa ana rabbana sauka yaa hásbinallah yaadzal alim yaa muhyin yaa kauyi yaa matiin

$$
\text { 0) ياربنا يامجيب انت السميع القريب_اله انت وسيع الرقيب فانظر الىالمؤمنين }
$$

5. Yaa rabbana yaamujiba antassami'na alkarib-Allahu anta wasi'a arrakiba fanadzarra aliyul mu'minin

$$
\text { T) نظرة تنزل الان م عنا ونن ذالمنا ـ الله ياء منا وكل الحنان مفيا رفى كل حين }
$$

6. Nadzarat tanazala alanmauna watanadzalna-Allahu yaa imanna wa kalaal hanani mafayan rafiikalahiina

$$
\text { V نسئلك بجاهه جد عليهم حدودالله يكسذالحسود ويد فع الظالمين }
$$

7. Nisaika bijahihi jada alaihim hadudallahu yakadzal hasuda widafa'i aldzalimin

$$
\text { ^) يزل للفقر ا ت يقيم الصاوات ـ الله ياء مر بالصا احا ت محب الصـا لحين يزح }
$$

8. Ya dalalil faqorot yaqiimussawaati-Allahu ya'muru bissahati mutibi assalahina yazah

$$
9 \text { 9 ) كل الحرم يكرم كل الطعام - الله يحد لبين الا نام يؤ من الخا مفين }
$$

9. Kalalharima yakarin kala thoaam-Allahu yahdilabinal inamayu'minil khafimin

$$
\text { ـ ( ) رب سقنا الخيش عام لنا فع مبارك الاو ام ـ الله يظال فى كل عام على ممر السنين }
$$

10. Rabsakna alhiisya aamilana faimabaarakallawaami Allahu yadzala fii kala mimassaniina

$$
\text { (1) ربنا شاكرينا وتو فنا مسلمين - الله حبعث من الامنين فئ زمرة السا بقين }
$$

11. Rabbana syaakarina wafaufana muslimin-Allahu habiats minal imnina fi zamarat assabikin 


$$
\text { r r ( ) بجاه طه الرسول جدناربنا بالقبول - اله هب لنا قول الرسولرب اسجب لنآمين }
$$

12. Bijaha thaha arrosulu jadina rabina balqhabuli-Allahu yaa fiika ama lana tauyali fajidana alassahin

ب ا ) عطاك ياب جليل و فعلك جميل - اله يا فيك امالنا طويل فجدنا على الصالحين 13. Atoka yaba jalii'a wafailka jamiila-Allahu yaafiika amalana tuyalifajidana alassohin

14. Ya rabba dzqqqal hadjina imana fa'ala malitaf-Allahu faahadina yafaqu ya

$$
\text { ـ ( ) يارب ذق الهدى ناءمن فعل مالايطف - اله فاهدنايفق يامجب الخالقين }
$$
majibalkholikin

$$
\text { 0 1) ياغفارلكل الذنوب ياستار لكل العيوب - اله ياكثاف لكل الكروب فاكسف للملؤمنين }
$$

15. Yaqhafarulkalam adzanuubi ya sataro likal ayubi-Allahu ya kasyafa likalkarub fakisfulilmu'minin

$$
\text { 7 } 1 \text { ) ثم الصلاة و السلام على شافع الا نام ـ الله يانعم اكر ام و الصحاب و البتا بعين }
$$

16. Tsuma assolaatu wassalamu ala syafaalanami-Allahu yaa naima ikrami wassahabi walbitatabiin

17. Yadzaljilal wakarim 3x mutana ala dubinalislam

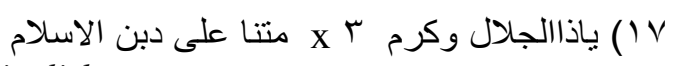

\section{Doa Minta Hujan}

Aku berlindung kepada Allah dari godaan setan yang terkutuk. Dengan nama Allah Yang Maha Pengasih lagi Maha Penyayang.

1. Wahai Yang Maha Penyayang 2x Ya Allah Yang Maha Penyayang, berilah kelapangan kepada kaum muslimin.

2. Wahai Tuhan kami Yang Maha Mulia. Wahai Tuhan Kami Yang Maha Penyayang, Ya Allah Yang Maha Pemurah lagi Maha Penyantun. Engkaulah pemberi nikmat terhadap orang-orang yang meminta pertolongan.

3. Kami tidak meminta selain kepada-Mu, karena kekuasaan-Mu sangat luas. Allah sudah ada sebelum semuanya binasa dan sebelum semuanya di dunia dan agama.

4. Tidak ada Tuhan kami selain-Mu ya Allah Yang Maha Berkecukupan, wahai Yang Maha Tinggi yang Maha Lemah, Yang Maha Kuat dan Teguh.

5. Wahai Tuhan Kami Yang Maha Mengabulkan engkau Maha Mendengar lagi Maha Dekat. Ya Allah engkau Maha Luas lagi Maha Menjaga, maka lihat oleh-Mu orang-orang mukmin.

6. Sebuah pemandangan berguguran para makhluk dan banyaknya cobaan-cobaan ya Allah, penderitaan tersebut ada setiap waktu terus-menerus. 
7. Kami mohon kepada-Mu berilah keteguhan kepada mereka hukum Allah memberantas orang-orang yang dengki dan membalas orangorang yang zalim.

8. Dosa akan gugur pada orang-orang yang bersalah apabila mereka sudah berselawat. Allah menyuruh orang-orang saleh mencintai kaum yang saleh juga.

9. Tiap-tiap yang haram menghilangkan kemuliaan makanan. Allah memisahkan antara makhluk yang mempercayai orang-orang penakut.

10. Ya Allah, turunkanlah hujan yang bermanfaat pada kami tahun ini, hujan yang memberi berkat selama-lamanya. Allah akan menurukannya tiap tahun kepada orang-orang yang giat bekerja

11. Ya Tuhan kami, kami selalu bersyukur dan menepati janji pada kaum muslimin. Allah mengirim orang-orang yang tepercaya pada kaum yang terdahulu.

12. Sebagai pengikut Rasul berilah keteguhan kepada kami, agar selalu dapat menerima apa yang kau beri. Ya Allah kabulkanlah kepada kami perkataan Rasul “Tuhan perkenankanlah/kabulkanlah untuk kami".

13. Ya Tuhan kebesaran-Mu yang dan perbuatan-mu yang bagus. Ya Allah pada-Mu lah kami menggantungkan harapan yang panjang, maka masukanlah kami ke dalam kelompok orang-orang yang saleh.

14. Ya Tuhan, berilah petunjuk kepada kami tidak perbuatan yang tidak pasti. Tunjukanlah kami tempat berpijak, wahai yang selalu menjawab/mendengar orang-orang yang berkesusahan.

15. Wahai Yang Maha Mengampuni sekalian doa-doa. Wahai Yang Maha Menutupi segala aib-aib. Ya Allah yang selalu membukakan jalan dalam setiap kesulitan-kesulitan, maka bukakanlah untuk orang-orang yang beriman.

16. Kemudian selawat dan salam kepada penolong makhluk (Rasulullah). Ya Allah berikanlah kepadanya nikmat yang mulia dan sahabat serta para pengikutnya.

17. Wahai Yang Maha Tinggi lagi Mulia 3x Wafatkanlah kami dalam agama Islam. 


\section{Fungsi Tradisi Armarohimin di Nagari Taram}

\section{Sebagai Sistem Proyeksi, yakni Sebagai Pencerminan Angan- angan Masyarakat Nagari Taram}

Tradisi Armarohimin sesungguhnya merupakan proyeksi keinginan dan angan-angan mereka yang sejak dahulu menginginkan kemakmuran. Dilihat dari sistem perekonomian mereka yang mayoritas sebagai petani, maka pengairan merupakan alat vital untuk keberhasilan panen mereka. Artinya, dengan melakukan tradisi ini mereka mengharapkan suatu keadaan cuaca yang stabil. Keadaan dimana hujan selalu turun tiap tahunnya, sehingga lahan pertanian mereka terairi dengan baik.

Mereka menganggap bahwa kedatangan musim kemarau merupakan suatu cobaan bagi mereka atas dosa-dosa yang telah diperbuat. Cobaan itu datang ditandai dengan serangan hama penyakit dan musim kemarau yang berkepanjangan dari Allah S.W.T. Oleh karena itu, dengan melakukan tradisi ini, mereka meminta permohonan kepada Allah S.W.T. agar diturunkan hujan melalui doa-doa yang berisi pujian dan pengampunan atas segala dosa yang telah mereka perbuat.

\section{Sebagai Alat Pengesahan Pranata-Pranata dan Lembaga-Lembaga Kebudayaan}

Tradisi Armarohimin berfungsi sebagai pengesahan dan pengukuhan sistem kebudayaan masyarakat Nagari Taram, terutama berfungsi sebagai kontrol untuk dipatuhinya norma dan aturan-aturan kebudayaan di tengahtengah masyarakat Nagari Taram. Artinya, di satu sisi keberadaan tradisi ini membantu masyarakat dalam upaya menjaga dan memelihara sistem norma dan ketentuan yang telah disepakati.

Pada sisi lain, tradisi Armarohimin ini berfungsi sebagai pengukuhan lembaga-lembaga yang ada pada masyarakat. Salah satu contoh lembaga tersebut adalah: Tuanku 21. Mereka berfungsi sebagai wadah atau lembaga tempat penyampaian pengaduan bagi masyarakat dan anggota suku mereka masing-masing agar tradisi Armarohimin dilakukan, jika kemarau panjang sudah melanda Nagari Taram. Mereka jugalah yang akan membicarakan, mengadakan rapat dan memutuskan kapan tradisi ini dilakukan.

Di samping itu, tradisi ini juga sebagai pengesahan surau tuo sebagai intitusi yang sangat berperan aktif di dalam pelaksanaan tradisi ini. Surau tuo memiliki sistem kepengurusan dan agenda-agenda yang telah mendapat 
persetujuan dan wewenang dari pemerintahan nagari, termasuk agenda pelaksanaan tradisi Armarohimin. Biasanya rapat tuanku 21 diadakan di surau tuo. Pelaksanaan tradisi ini juga di mulai dan berakhir di surau tuo. Bahkan dalam pemilihan pemimpin atau imam dalam pelaksanaan tradisi Armarohimin tidak terlepas dari peran pengurus surau tuo.

Oleh karena tanggung jawab imam yang sangat besar dalam tradisi ini, maka dalam pemilihannya memiliki pertimbangan-pertimbangan yang cukup rumit, hal ini dilakukan untuk menjaga kesakralan tradisi ini. Pertimbangan-pertimbangan itu berupa : a) umur seorang imam dalam tradisi Armarohimin minimal 40 tahun, hal ini berdasarkan kematangan dan kedewasaan seseorang dalam memimpin; b) tingkat pengetahuan agama, tidak semua ustadz atau guru mengaji bisa menjadi imam. Hal ini berdasarkan pemahaman masing-masing mereka yang berbeda terhadap Tradisi Armarohimin dan isi ayat yang terkandung di dalamnya; c) merupakan warga masyarakat Nagri Taram asli, hal ini untuk menepis kecemasan adanya upaya untuk mengurangi kesakralan tradisi ini bagi masyarakat setempat.

Semua pertimbanganitu diberikan karena untuk menjaga keberadaan tradisi ini agar tidak mengalami kepunahan atau perubahan. Apalgi pada saat sekarang ini yang sedang maraknya beredar aliran-aliran dan tarikat pengajian baru yang tidak sesuai dengan pemahaman agama masyarakat Nagari Taram dan Tradisi Armarohimin itu sendiri

\section{Sebagai Alat Pendidikan dalam Masyarakat Nagari Taram}

Di dalam pelaksanaan tradisi Armarohimin juga berfungsi sebagai alat pendidikan bagi masyarakat Nagari Taram. Pelajaran yang dapat diambil terutama mengenai hubungan antara manusia dan Tuhannya, bahwa manusia hanyalah makhluk yang lemah dihadapan-Nya. Setiap perbuatan yang telah dilakukan oleh setiap manusia, baik ataupun buruk akan mendapat ganjaran yan setimpal. Selain itu, hanya kepada-Nyalah mereka memohon ampunan atas setiap yang telah diperbuat.

Tradisi Armarohimin juga memiliki fungsi pendidikan dan pengajaran bagi anak-anak. Pada saat melakukan prosesi Armarohimin mengelilingi kampung, orang tua biasanya akan memberi tahu bahwa kegiatan tersebut sedang dilangsungkan. Orang tua akan memberikan pemahaman yang singkat tentang tradisi ini, dengan harapan anaknya akan mengerti maksud dan tujuan dari tradisi Armarohimin ini. 


\section{Sebagai Alat Pemaksa Dan Pengawas Agar Norma-Norma Masyarakat Selalu Dipatuhi Anggota Kolektifnya}

Fungsi yang terkahir dari tradisi Armarohimin yakni sebagai alat pemaksa dan pengawas agar norma-norma masyarakat di nagari ini selalu dipatuhi oleh masyarakatnya. Melalui tradisi ini, seluruh anggota masyarakat diajak dan dituntut untuk mampu menjadi pengawas dan kontrol terhadap segala tindakan dan tingkah laku masyarakat secara luas. Selanjutnya setiap pemuka masyarakat hendaknya mampu memberikan contoh dan teladan yang baik kepada masyarakat. Dengan berjalannya norma-norma dengan baik di tengah-tengah masayarakat, mereka berharap nagari ini akan jauh dari musibah dan malapetaka.

\section{Penutup}

Sementara itu, tidak seluruh masyarakat Taram memiliki pemahaman yang sama dalam memahami tradisi tersebut. Ada sebagaian masyarakat yang menganggap tradisi ini sebagai ritual untuk memohon hujan kepada makhluk halus berupa jin-jin penunggu tempat-tempat keramat yang ada di Nagari Taram. perjalanan yang ditempuh dalam melakukan Armarohimin merupakan tempat-tempat menurut anggapan masyarakat Taram merupakan tempat keramat.

Hal tersebut dapat dibenarkan, oleh karena sampai saat ini masyarakat Taram masih berpegang teguh terhadap kepercayaan lama mereka berupa percaya terhadap takhayul. Walaupun mereka muslim yang taat, akan tetapi kepercayaan tersebut masih dipergunakan sebagai warisan dari nenek moyang mereka. Hal ini disebabkan oleh karena ada sebuah ketakutan, seandainya kepercayaan tersebut dilanggar dipercaya akan adanya musibah yang datang sebagai ganjaran dari pelanggaran tersebut.

\section{Daftar Pustaka}

Agus, Bustanul. 2006. Agama dalam Kehidupan Manusia. Jakarta: PT. Rajagrafindo Persada.

Bungin, Burhan (ed). 2004. Surau: Pendidikan Islam Tradisional dalam Transisi dan Modernisasi. Jakarta: Logos Wacana Ilmu.

Azra, Azyumardi. 2003. Surau: Pendidikan Islam Tradisional dalam Transisi dan Modernisasi. Jakarta: Logos Wacana Ilmu.

Danandjaja, James. 1982. Folklor Indonesia. Jakarta: PT Pustaka Utama Grafiti. Endraswara, Suwardi. 2003. Metodologi Penelitian Kebudayaan. Yogyakarta: 
Ilham Halid

Gadjah Mada University Press.

Esten, Mursal. 1999. Kajian Transformasi Budaya. Bandung: Penerbit Angkasa.

Morris, Brian. 2003. Antropologi Agama: Kritik Teori-Teori Agama Kontemporer. Yogyakarta: AK. Group.

Navis. A.A. 1986. Alam Terkembang Jadi Guru. Jakarta: Pustaka Grafitipers.

Profil Nagari Taram Tahun 2008 Kecamatan Harau Kabupaten Limapuluh Kota.

Vredenbergt, Jacob. 1980. Metodologi dan Teknik Penelitian Masyarakat. Jakarta: PT Gramedia. 